\title{
Implementação de Políticas Públicas de Assistência Estudantil: estratégias organizacionais na perspectiva da efetividade
}

\section{Implementation of Public Policies for Student Assistance: organizational strategies in the effectiveness perspective}

\author{
WANDILSON ALISSON SILVA LIMA* \\ EDUARDO DAVEL **
}

\section{RESUMO}

O objetivo deste artigo é discutir, descrever e propor estratégias organizacionais de implementação de políticas públicas de assistência estudantil ancoradas na efetividade. A perspectiva da efetividade de Sandfort e Moulton (2015) proporciona a implementação de políticas orientadas pela mudança almejada e enfrentamento prático dos desafios encontrados. A metodologia desta pesquisa é de abordagem qualitativa, apoiada em estudo de casos de Instituições Federais de Ensino Superior. A coleta de dados foi obtida por meio de documentos, entrevistas semiestruturadas e observações diretas. As análises das informações foram realizadas a partir dos principais processos de implementação: estabelecer opções viáveis, identificar a lógica da mudança, coordenação das atividades, fluxos do processo e avaliação das políticas na implementação da assistência estudantil. Os resultados da pesquisa discutem e fornecem um conjunto de estratégias para cada um desses processos, mantendo-se a aderência ao contexto da assistência estudantil. Essas estratégias organizacionais, suas

* UFBA. wandilsonn@gmail.com .

* EAUFBA. Professor na Escola de Administração da Universidade Federal da Bahia. Ph.D. em administração pela École des hautes études commerciales de Montreal. Editor da RIGS - Revista interdisciplinar de gestão social, publicada pelo CIAGS - Centro interdisciplinar de gestão social da UFBA. davel.eduardo@gmail.com . 
implicações e aplicações em outros contextos são apresentadas e discutidas.

Palavras-chave: Assistência estudantil. Estratégias organizacionais. Implementação de políticas públicas. Perspectiva da efetividade.

\section{Abstract}

The research's goal is to discuss, describe and propose organizational strategies for implementing public policies of student assistance based on effectiveness. The effectiveness perspective proposed by Sandfort and Moulton (2015) provides an implementation of targeted change policies and practical solution to the challenges encountered. The research's methodology is a qualitative approach, based on the case study of Federal Institutions of Higher Education. Data collection was obtained through documents, semi-structured interviews and direct observation. The analysis was carried out and structured around the main implementation processes: identify viable options, identify a logic of change, coordinate activities, process flows and policy evaluation in the implementation of student assistance. The research results discuss and provide a set of strategies for each processes, considering the context of student assistance. These organizational strategies, its implications and applications in other contexts are presented and discussed.

Key-words: Student assistance. Organizational Strategies. Implementation of public policies. Perspective of effectiveness.

\section{INTRODUÇÃo}

A implementação de políticas públicas ocorre quando o planejamento coloca ações em prática, envolvendo tomadas de decisão e execução dos planos diante dos objetivos propostos (PRESSMAN; WILDAVSKY, 1984; HILL, 1993; FREY, 2000, SARAIVA; FERRAREZI, 2006; FARIA 2012; SECCHI, 2014; SANDFORT; MOULTON, 2015; WU et al., 2014). Vários especialistas argumentam que, durante a etapa de implementação, é possível identificar os principais desafios enfrentados na gestão das políticas públicas com o propósito de mapear os problemas e buscar soluções estratégicas (SECCHI, 2014).

Os desafios enfrentados no processo de implementação são inúmeros, entretanto existem fatores mais referenciados pelas pesquisas 
em relação ao fracasso das políticas públicas, entre os quais se destacam a comunicação dos objetivos e estratégias pretendidas pelos formuladores e implementadores (LIMA; D'ASCENZI, 2013). Esse insucesso na implementação de políticas públicas decorre das falhas advindas pela carência de um olhar mais prático, principalmente devido ao distanciamento e à ausência de visão holística, integrada e sistêmica dos formuladores para com os implementadores (WU et al., 2014). Estudiosos aconselham uma agenda de pesquisa em implementação de políticas públicas voltada para temas relacionados com estratégias organizacionais (OLLAIK; MEDEIROS, 2011).

Quando se trata de implementação de políticas no âmbito educacional, percebe-se que o direito à educação sempre esteve presente nas constituições brasileiras como marco legal. Portanto, somente no final dos anos de 1970 e início dos anos de 1980, frente à crise mundial do sistema capitalista e da reforma do Estado brasileiro, o ensino superior começou a ser repensado como política pública (DIAS, 2007). Sabe-se que o acesso à Educação Superior, no Brasil, é um tema bastante relevante na universidade, diante da crescente demanda social e até mesmo mercadológica. Entretanto, somente com a implantação do Decreto 7.234, de 19 de julho de 2010, foi instituído o Programa Nacional de Assistência Estudantil - PNAES, que tem como finalidade "ampliar as condições de permanência dos jovens na educação superior pública federal” (BRASIL, 2010). Todavia, o conjunto das políticas de assistência estudantil gerido pelas Instituições Federais de Ensino Superior - IFES, que compõem esse programa, defronta-se com vários desafios durante o processo de implementação. A efetividade dessa implementação, buscando a permanência do estudante, é um conhecimento determinante para o planejamento e a gestão governamental, no contexto das IFES.

O objetivo deste artigo é discutir, descrever e propor estratégias organizacionais de implementação de políticas públicas de assistência estudantil ancorada na efetividade. Neste estudo, enfatizaram-se as estratégias oriundas no nível organizacional, já que as organizações, como ator social, funcionam como agentes integradores entre o arranjo da política no nível governamental e sua operacionalização. Para alcançar esse objetivo, buscou-se uma perspectiva que considerasse a efetividade de forma central e sistemática. Com efeito, diversos 
trabalhos sobre a implementação de políticas públicas ainda são pautados somente na descrição e as análises dos programas sociais que, geralmente, consistem em apresentar genericamente o modo como as políticas estão sendo implementadas.

A perspectiva proposta por Sandfort e Moulton (2015) demonstra que a gestão pública pode explicitar práticas efetivas e inovadoras, planejando a mudança que apoie o avanço da temática em questão. Isso é possível quando ocorre a categorização e sistematização de ações bem-sucedidas durante o processo de implementação da política no que se refere aos múltiplos níveis, a saber: político, organizacional e operacional. Assim, a efetividade da implementação decorre da mudança proposta à organização, em que os resultados desejados por ela estejam bem definidos e disseminados, de maneira integrada, gerando valor público para os atores sociais envolvidos. Portanto, os implementadores, por intermédio de suas experiências, podem revelar como suas práticas corroboram para melhorar as condições e promover a mudan ça perante recursos e estruturas disponíveis. Neste momento, as estratégias são discutidas a fim de impactar efetivamente o processo de implementação das políticas públicas (SANDFORT; MOULTON, 2015).

Não há dúvida que as estratégias organizacionais efetivas garantem uma implementação suscetível à geração de valor para o público-alvo das políticas públicas. Portanto, o estímulo para encarar os desafios da permanência dos discentes, que é tão relevante para o ensino superior brasileiro, dá-se por meio de estratégias identificadas e categorizadas efetivamente. Na medida em que as políticas públicas de assistência estudantil forem implementadas sob a perspectiva da efetividade, tornam-se contribuições potencias e reais a ser experimentadas pelos gestores organizacionais das IFES.

Este artigo foi estruturado em cinco partes, além desta introdução e da conclusão. Na sequência, apresentou-se a perspectiva da efetividade para a implementação de política pública. Na seção posterior, a importância e os desafios das políticas públicas no nível organizacional foram apresentados. Em seguida, explicamos a metodologia da pesquisa e os resultados da pesquisa, exibidos na forma de estratégias efetivas na implementação das políticas públicas de assistência estudantil. Por fim, os resultados, seus impactos e sua aplicabilidade são discutidos. 


\section{A PERSPECTIVA DE EFETIVIDADE NA IMPLEMENTAÇÃo DE Políticas Públicas}

A implementação é uma das etapas do ciclo de políticas públicas onde ocorre também a análise dos resultados e dos impactos das ações e políticas que não foram devidamente planejadas na fase de formulação. Nesse processo de implementação, são apreciadas as vertentes tanto no que se refere aos mecanismos administrativos e o desempenho dos atores envolvidos quanto da característica e técnica dos projetos ou programas (FREY, 2000). Nessa etapa, os principais elementos de análise são pessoas e organizações que estão diretamente relacionadas com instituições, recursos e pressões externas (SECCHI, 2014).

A implementação é tanto um processo, onde se constitui a política até o seu impacto final; quanto somente uma parte de ações governamentais acerca de decisões legislativas a fim de colocá-las em prática na realização das políticas (PEREZ, 2010). Todavia, há uma consonância em dizer que a implementação pode dar-se no momento em que os objetivos traçados, por meio do processo decisório, revelam-se em ações práticas. Neste sentido, quando os objetivos são atingidos no processo de implementação de políticas públicas, traduzem resultados efetivos (HILL, 1993; SARAIVA; FERRAREZI, 2006; WU et al., 2014).

As mudanças sociais, econômicas e ambientais são inerentes às organizações, portanto os problemas que surgem muitas vezes devem ser resolvidos por meio não somente da formulação de políticas públicas, mas também no desenvolvimento de novos programas e iniciativas. Diversos pesquisadores têm se voltado para analisar essas mudanças, criando formas de entender como essas iniciativas e a implementação de políticas podem ser aprimoradas no sentido de resolver os problemas diante de sua complexidade. Então, o estudo da implementação pode ser ampliado em dispor instrumentos estratégicos de melhorias práticas, de forma que proporcionem resultados efetivos frente a essa complexidade (SANDFORT; MOULTON, 2015). Assim, esse momento atual da implementação voltado para a efetividade é denominado de perspectiva contemporânea que se estende à esfera pública.

Quando se refere ao campo de políticas públicas, a implementação precisa criar valor público e produzir resultados para garantir 
que a mudança seja almejada por todos os envolvidos no sistema de implementação. Isso é possível quando os atores sociais estão engajados na busca desses resultados. Portanto, essas pessoas envolvidas (gestores, executores e outros) que almejam por melhorias de programas do governo devem procurar apreciar os níveis em que são formuladas e executadas as políticas dentro da complexidade social. Para cultivar a prática de implementação, os participantes e os recursos, fontes de poder, e valores culturais precisam ser identificados, sendo necessário também conhecer o contexto em que se pode afetar a mudança. Nesse aspecto, três níveis compõem o sistema de implementação, demonstrando como as políticas podem se tornar efetivas a partir das práticas vivenciadas (SANDFORT; MOULTON, 2015). O Quadro 1 sistematiza os múltiplos níveis do sistema de implementação.

Quadro 1 - Múltiplos Níveis do Sistema de Implementação na Perspectiva da Efetividade

\begin{tabular}{|l|l|l|l|}
\hline Nível & Foco de Análise & Principais Processos & Principais Atividades \\
\hline Campo político & $\begin{array}{l}\text { Redes limitadas entre } \\
\text { organizações que de- } \\
\text { senvolvem uma política } \\
\text { substantiva e área de } \\
\text { programa em determi- } \\
\text { nado local }\end{array}$ & $\begin{array}{l}\text { Montar instrumentos } \\
\text { políticos e recursos de } \\
\text { implementação } \\
\text { Criar estruturas de } \\
\text { campo }\end{array}$ & $\begin{array}{l}\text { Problemas e soluções } \\
\text { são negociados } \\
\text { Autoridade e recursos } \\
\text { são mobilizados } \\
\text { Estruturas coordena- } \\
\text { das são selecionadas }\end{array}$ \\
\hline Organização & $\begin{array}{l}\text { Autorização e serviços } \\
\text { de organizações que } \\
\text { formulam as regras e } \\
\text { estruturas }\end{array}$ & $\begin{array}{l}\text { Integrar programa } \\
\text { com processo organi- } \\
\text { zacional existente } \\
\text { Criar a estrutura de } \\
\text { programa }\end{array}$ & $\begin{array}{l}\text { Programa é opera- } \\
\text { cionalizado com ativi- } \\
\text { dades definidas } \\
\text { Recursos são garanti- } \\
\text { dos e atribuídos para } \\
\text { entregar programa }\end{array}$ \\
\hline $\begin{array}{l}\text { Linha de frente } \\
\text { (Operacional) }\end{array}$ & $\begin{array}{l}\text { Trabalhadores ou } \\
\text { interfaces que integrem } \\
\text { diretamente a popula- } \\
\text { ção-alvo para realizar o } \\
\text { programa }\end{array}$ & $\begin{array}{l}\text { Decretar (promulgar, } \\
\text { ordenar, legalizar) } \\
\text { o programa para o } \\
\text { grupo-alvo }\end{array}$ & $\begin{array}{l}\text { Recursos e serviços } \\
\text { são entregues } \\
\text { Avaliações de quali- } \\
\text { dade ocorrem } \\
\text { com o programa }\end{array}$ \\
\hline
\end{tabular}

Fonte: Sandfort e Moulton (2015, p. 24)

Os níveis de implementação de política trazidos por Sandfort e Moulton (2015) estão divididos em campo político, organizacional e linha de frente (operacional). Eles objetivam a implementação 
efetiva através desse sistema integrado. No campo político, a organização está focada na formulação da política, abrangendo recursos e instrumentos para o desenvolvimento das ações normativas e legais do programa. No nível organizacional, as organizações são responsáveis por criar regras e estruturas que integrem o processo de implementação entre o elaborador e o executor das políticas. $\mathrm{O}$ nível operacional é composto por trabalhadores que executam as políticas para o público-alvo, fornecendo recursos e serviços previstos nas esferas anteriores. Desse modo, os desafios técnicos e adaptativos necessários precisam ser compreendidos pela gestão como mobilizadores da mudança organizacional, aplicando investigação analítica e habilidade social (LIMA; DAVEL, 2016).

Faz-se necessário identificar a lógica da mudança, investigando de que forma o programa pode gerá-la na população-alvo, analisando o comportamento desse grupo e a efetividade das atividades selecionadas e implementadas pelos trabalhadores. Outro fator é a coordenação dessas atividades, observando os objetivos, estruturas, tecnologias e comunicação de todos os envolvidos. Todavia, uma solução apresentada seria a padronização de programas, que precisa ser acompanhada pela supervisão e especialização das tarefas nas quais exigem conhecimentos específicos (SANDFORT; MOULTON, 2015).

Por fim, traz-se o programa de núcleo (central), no seu conjunto, onde o processo de implementação ocorre quando há conformidade a respeito da natureza do problema e as ações interventoras são efetivas. O núcleo político, denominado de policy core, é composto por normas que procuram avaliar o bem-estar como finalidade das políticas públicas frente à construção social e valorativa dos atores do sistema nos distintos instrumentos e níveis governamentais. Quando o programa surge de uma legislação específica, na ótica de contextos sociais distintos, os atores sociais buscam a construção de algo novo diante da racionalidade imposta pela lei. $\mathrm{O}$ entendimento dos aspectos informais e valores dos participantes do programa é mais presumível dentro do sistema social (BARBOSA VICENTE, 2015, p. 82; SANDFORT; MOULTON, 2015).

Os fatores encontrados nas pesquisas contemporâneas são atributos que objetivam propor uma perspectiva mais prática da implementação pautada na efetividade da implementação (HILL; HUPE, 2014; SECCHI, 2014; WU et al., 2014; SANDFORT; MOULTON, 2015; 
SAUNDERS, 2016). Assim, as principais vantagens no processo de implementação política foram denominadas de caraterísticas da perspectiva da efetividade: criação de valor público, atores sociais engajados no processo de implementação, implementação em sistema de múltiplos níveis, mudança social, decisões coletivas, análises empíricas da política, ações coletivas e participação conjunta (LIMA; DAVEL, 2016, p. 7). Desse modo, a perspectiva da efetividade, que foi apresentada, é adotada devido a todas essas vantagens e principalmente porque propõe que as práticas da implementação sejam consideradas nas políticas públicas.

\section{A implementação efetiva de Política Pública aplicada EM nível organizacional}

\subsection{Organizações como Campo de Ação Estratégica}

Há uma defesa em que a ideia das decisões coletivas deve ser preferida quando é comparada por estratégias estreitamente individuais. Logo, o argumento é que a dimensão da governança vai além do desempenho do governo, perpassa as ações para outros níveis de atores sociais que estejam correlacionados com o contexto. Dessa forma, rompem-se os paradigmas de implementação do passado para as análises empíricas da política (HILL; HUPE, 2014). Ao se buscar melhores resultados para proporcionar a mudança sistêmica, o principal passo é o desenvolvimento de subsídios para alcançar fins desejados. Isso é possível por meio da implementação do programa central, cujos atores sociais realizam ações operacionais no campo de ação estratégica. Uma dessas ações se dá com o estabelecimento de opções que precisam ser consensualmente desejáveis e viáveis, considerando a influência da infraestrutura e da experiência inter e/ou intraorganizacional (SANDFORT; MOULTON, 2015).

A proposta de mudança e a ordem social para o progresso podem ser compreendidas por meio da teoria do campo de ação estratégica que está relacionada com os níveis de implementação (FLIGSTEIN; MCADAM, 2011). Para tanto, os campos de ação são “uma 'ordem social' de nível meso, socialmente construídas, nas quais atores (individuais ou coletivos) interagem uns com os outros na base de entendimentos compartilhados sobre os propósitos, relacionamentos com outros e as regras do campo" (FLIGSTEIN; 
McADAM, 2011, p. 3, tradução do autor). Dessa forma, os campos de atuação estratégica são compreendidos pelas ações coletivas e participação conjunta que os atores sustentam seus propósitos, relacionamentos e regras para guiar o desempenho das atividades. Apesar de existir uma diversidade de atividades em níveis diferentes, no ambiente de implementação política, onde se pretende atingir um objetivo comum, estão presentes os elementos que compõem o campo. A estrutura social de cada campo de ação estratégica é o centro da análise da implantação onde ocorrem as alterações e mudanças organizacionais, por essa razão está situada no núcleo do programa. Cada instituição tem seus próprios recursos, participantes e experiências próprias de sua estrutura social, porém, há um desejo em comum de descobrir o que fazer e como obter recursos compartilhados (SANDFORT; MOULTON, 2015).

Para a implementação bem-sucedida, recomendam-se três processos imprescindíveis nos campos de ação estratégica: a) estabelecer opções viáveis ou objetivos alcançáveis perante as possíveis limitações; b) identificar a lógica da mudança desejada pela população-alvo; e c) estruturar a coordenação. No primeiro processo, os programas que compõem uma política pública, consideram a autoridade política, os recursos e os participantes integradores. Então, a legalidade e as regulamentações formais influenciam, de certo modo, a concepção da política na tomada de decisão das organizações. Além do mais, o ambiente de expectativas da população-alvo, as crenças e valores que compõem a cultura são fatores determinantes para que os gestores organizacionais busquem implementar mudanças que sejam efetivas. No segundo processo, as organizações necessitam ser agentes integradores, diante de sua autoridade e capacidade interna, recomendando inclusive as principais ações para a resolução dos problemas e conflitos surgidos na implementação. Para isso, os gestores devem capacitar-se e replicar os conhecimentos adquiridos a fim de trocar experiências que permitam resultados efetivos na implementação. Por fim, o terceiro processo menciona a coordenação, formada por intermédio de estruturas formais e informais, nas quais as organizações pretendem atingir os seus objetivos. Associado à estrutura formal, pode-se mencionar a questão da formalização, onde o controle hierárquico, a supervisão, as regras, as normas e os procedimentos organizacionais orientam o processo de tomada de decisão. Enquan- 
to, de modo mais informal, estão os elementos mais relacionados à cultura interna da organização (SANFORT; MOULTON, 2015).

Há também uma segunda dimensão que versa sobre a aplicação dessa análise organizacional, a qual consiste em desenhar o fluxo do processo e auditoria (avaliação) da integração do programa durante a implementação. Com relação à análise de fluxo do processo do programa, faz-se necessário a criação de uma ferramenta padrão de gerenciamento de projeto que contenha as atividades, etapas e sequência do programa a fim de que os envolvidos tenham clareza no desempenho de suas tarefas. Por sua vez, a autoria do programa de uma organização visa verificar a compatibilidade com a integração e a possibilidade de redesenhá-lo. Nesse quesito, é avaliado como o programa se relaciona com outras atividades da organização e o grau de conformidade entre os resultados e o esperado na geração de valor público, propondo alterações e melhorias quando for necessário. Esses fatores, que buscam a efetividade da implementação das políticas, são imprescindíveis e são complexos para o processo racional de tomada de decisão, porém não se pode dizer que eles sejam os únicos a serem desenvolvidos na prática dos implementadores (SANDFORT; MOULTON, 2015).

A compreensão dessa temática é fundamental na gestão das políticas que tenham aderência na prática sob a ótica dos atores sociais que se situam em distintos níveis no sistema de implementação. Nessa perspectiva de ação estratégica, a teoria geral da mudança social emerge das interações dos atores sociais que ocorrem, sejam entre si ou com o contexto no qual estão inseridos, de maneira individual ou coletiva. Assim, o aspecto de campo pode ser utilizado com o propósito de compreender as relações dos atores sociais onde as organizações estão inseridas, dentro das instituições e entre os distintos momentos de decisão na constituição das práticas das políticas públicas (FLIGSTEIN; MCADAM, 2012).

As organizações, como campos de ação estratégica, diante de suas prioridades e dos diversos programas, competem por tempo, recursos e atenção no processo de implementação de políticas públicas. Os implementadores, por sua vez, são parte do contexto organizacional e precisam estar comprometidos em entender as prioridades, de modo que a mudança de determinado programa seja efetiva. Então, algumas questões necessitam ser refletidas no 
momento de decidir os caminhos a serem trilhados, considerando todos os agentes envolvidos na ação, tais como: Quais programas e/ou ações têm prioridade? Onde o programa se situa dentro da estrutura organizacional? Qual a necessidade de acompanhamento na realização das tarefas? Que recursos são dedicados a tarefas imprescindíveis? Há fatores que influenciam as organizações na implementação de políticas públicas, entre os quais, o ambiente externo, o campo da política, os recursos, as expectativas dos atores sociais, as estruturas de coordenação, os processos internos e outros (SANDFORT; MOULTON, 2015).

A mudança política dentro da organização pode ser praticada em três processos: a) determinar como as decisões são tomadas na organização; b) identificar possíveis influências no processo de tomada de decisão dentro do ambiente e selecionar estratégias apropriadas; e c) desenvolver estratégias apropriadas para facilitar a decisão com base nos fatores que influenciam o cenário (SAUNDERS, 2016). O estreitamento nos estudos entre as estratégias e políticas públicas, sobretudo na esfera governamental, é de suma relevância para subsidiar as organizações públicas. Sobre essa relação que reside na fundamentação de estratégia e política pública, a gestão está entre os desafios da ação estratégica (BERGUE, 2011). Ainda que as organizações pertençam a um único sistema, pode haver variabilidade nas decisões, sendo necessário identificar os desafios e as diferentes abordagens, de modo que o compartilhamento das estratégias possa auxiliar a outras instituições.

\subsection{Implementação de Políticas Públicas: Desafios para Gestores}

Com base nas pesquisas, o Quadro 2 apresenta um modelo de análise de implementação de políticas considerando as organizações públicas, no caso desta pesquisa às IFES, como campos de ação estratégica. Esse quadro foi construído a partir do arcabouço composto por dimensões e processos (SANDFORT; MOUTON, 2015) e pelos desafios que foram articulados com as visões de diversos autores (LEMAN, 2002; BERGUE, 2010; CARVALHO; BARBOSA; SOARES, 2010; FARAH 2011; LIMA; D'ASCENZI, 2013; PARK; RETHEMEYER, 2014; WU et al., 2014) do processo de implementação de políticas públicas. A primeira dimensão incide em uma análise de desenvolver 
um programa compatível com os parâmetros, funcionamento relacionado com as regras e processos e especificidades da organização. A segunda dimensão consiste em uma análise de aplicação do programa a fim de identificar o fluxo do processo e fazer uma auditoria referente à avaliação da integração frente aos parâmetros organizacionais. Destarte, o foco principal da implementação é analisar as dimensões do programa, objetivando verificar como a organização pode contribuir para a integração e da política posta em prática (SANDFORT; MOULTON, 2015). Os principais desafios descritos e propostos são inerentes ao contexto das organizações responsáveis por implementar as políticas e impactam outros níveis do sistema de implementação.

\section{Quadro 2 - Implementação de Políticas Públicas no Nível Organizacional}

\begin{tabular}{|c|c|c|}
\hline Dimensões & Processos & Desafios \\
\hline \multirow{3}{*}{$\begin{array}{l}\text { Análise da } \\
\text { integração do } \\
\text { programa }\end{array}$} & $\begin{array}{l}\text { Estabele- } \\
\text { cer opções } \\
\text { viáveis }\end{array}$ & $\begin{array}{l}\text { Ausência de mecanismos para melhorias contínuas no processo } \\
\text { organizacional de implementação } \\
\text { Limitações de propostas em relação aos recursos necessários à } \\
\text { implementação } \\
\text { A má concepção da política em relação à missão dos programas/ } \\
\text { projetos } \\
\text { O ambiente, as expectativas da população-alvo e as crenças e valores } \\
\text { que compõem a cultura geralmente são desconsiderados }\end{array}$ \\
\hline & $\begin{array}{l}\text { Identificar } \\
\text { a lógica da } \\
\text { mudança }\end{array}$ & $\begin{array}{l}\text { Falta de integração entre os atores sociais agenciados pela orga- } \\
\text { nização } \\
\text { O gerenciamento de demandas inadiáveis pode ser falho } \\
\text { Ausência de estímulos ao compartilhamento das informações, } \\
\text { replicação dos conhecimentos e troca de experiências intra e } \\
\text { interorganizacional } \\
\text { Carência na capacitação de pessoal voltada para a implementa- } \\
\text { ção efetiva das políticas públicas }\end{array}$ \\
\hline & $\begin{array}{l}\text { Coordenar } \\
\text { atividades }\end{array}$ & $\begin{array}{l}\text { Excesso de burocracia e formalidade na gestão das políticas } \\
\text { Incongruências no estabelecimento de metas e objetivos organiza- } \\
\text { cionais comuns } \\
\text { A informalidade e a cultura interna são muitas vezes desconsideradas } \\
\text { Falhas nos mecanismos de supervisão e controle } \\
\text { Ausência de procedimentos e normas na elaboração e execução das } \\
\text { atividades } \\
\text { Gestão de desempenho imprecisa sobre a implementação das políticas }\end{array}$ \\
\hline \multirow[b]{2}{*}{$\begin{array}{l}\text { Análise orga- } \\
\text { nizacional da } \\
\text { aplicação }\end{array}$} & $\begin{array}{l}\text { Fluxo do } \\
\text { processo das } \\
\text { políticas e } \\
\text { programa }\end{array}$ & $\begin{array}{l}\text { Falta de uma ferramenta padrão de gerenciamento do projeto } \\
\text { Carência de instrumentos que capturem o fluxo do processo do } \\
\text { programa }\end{array}$ \\
\hline & $\begin{array}{l}\text { Auditoria } \\
\text { das políticas }\end{array}$ & $\begin{array}{l}\text { Ausência de avaliações/auditorias da concepção de implementa- } \\
\text { ção do programa } \\
\text { Faltam avaliações/auditorias da integração com as particularida- } \\
\text { des do programa } \\
\text { Ferramentas ineficazes de acompanhamento dos resultados da } \\
\text { política para o público }\end{array}$ \\
\hline
\end{tabular}

Fonte: Elaboração própria (2017). 
A partir desse mapeamento dos desafios durante a implementação de políticas públicas, é notória a necessidade de desenvolver melhorias contínuas nos processos por meio do mapeamento das atividades executadas. Nota-se que as demandas inadiáveis não são voltadas para o gerenciamento da implementação. No que tange à comunicação dos objetivos e estratégias almejadas pelos formuladores e implementadores, os mecanismos geralmente são desestruturados e ineficazes. Nesse sentido, a clareza quanto à missão dos programas/projetos das políticas públicas fica comprometida, refletindo de forma negativa, com compreensões diferentes pelos envolvidos na implementação. O processo de mudança é desintegrado entre os níveis e atores sociais inseridos na implementação devido ao fato de cada estrato se guiar pela ótica de seus interesses. Um desafio da implementação relaciona-se com as limitações dos recursos (financeiros, tecnológicos, de pessoal, infraestrutura e outros), de suporte político e burocrático, impedindo a efetividade e o progresso das políticas públicas. Assim, a incapacidade técnica na gestão dos recursos e na coordenação de rede são gargalos que as organizações públicas necessitam enfrentar os resultados das políticas. Além disso, os incentivos para os implementadores, que estão rotineiramente próximos aos problemas, por sua vez, são insuficientes e/ou inexistentes, porque são excluídos na tomada de decisão das políticas públicas (BERGUE, 2010; LIMA; D’ ASCENZI, 2013; WU et al., 2014).

Os principais desafios que interrompem a implementação de políticas públicas são: a) pertinente à missão; b) ausência de suporte político e burocrático; c) capacidade operacional. No primeiro desafio, a barreira de implementação é centrada nas múltiplas visões, geralmente vagas e incoerentes. A segunda está relacionada a questões de cunho político, expressa na morosidade da autorização dos recursos dado o conflito de interesse existente, ausência de apoio nas ações de outros atores sociais e falta de incentivo aos implementadores correspondentes à complexidade das atividades desempenhadas. No terceiro desafio, as barreiras consoantes residem nas limitações dos recursos no momento da entrega dos serviços à população-alvo, na falha dos planos operacionais quanto à clareza 
de seus objetivos e a falta de capacidade de coordenação de rede e estrutura de gestão (WU et al., 2014).

Tem-se repensado alguns paradigmas modernos, em que se discute, inclusive, o papel das políticas públicas, questionando sua abrangência e principalmente sua efetividade institucional. Então, para torná-las efetivas na sua implementação, as políticas públicas devem ser referenciadas para a sustentabilidade, mencionando a inclusão de diversas ações e atores nessa acepção (MATIAS-PEREIRA, 2012). Nesse sentido, da mesma maneira que as políticas governamentais podem aprovisionar oportunidades, também existe a possibilidade de limitar negociações estratégicas por meio de regras estabelecidas no âmbito organizacional (BATEMAN; SNELL, 2006).

As estratégias dos gestores no momento da implementação de políticas públicas são conduzidas de forma integrada. Para tanto, os gestores dessas políticas precisam atuar na prática os planos que foram formulados, sendo assim mais criativos e empreendedores diante dos recursos organizacionais disponíveis (WU et al., 2014). As pesquisas podem se tornar mais benfazejas no que tange a perpassar o campo teórico por intermédio do desenvolvimento de instrumentos governamentais mais efetivos. Nesse sentido, precisam empreender esforços para compreender as percepções das estratégias, normatividades e intencionalidades dos atores sociais, sobretudo nas esferas de políticas de educação (LIMA; D'ASCENZI, 2013). O Quadro 3 expõe as finalidades da implementação integrada e as tarefas de implementação nas quais estão contidas nos desafios dos gestores.

\section{Quadro 3- Finalidades e Tarefas de Implementação Integrada}

\begin{tabular}{|l|l|}
\hline Finalidades & Tarefas \\
\hline $\begin{array}{l}\text { Formar grupos favoráveis à mudança de políticas } \\
\text { públicas entre uma gama de stakeholders }\end{array}$ & $\begin{array}{l}\text { Identificar indivíduos e unidades intraorga- } \\
\text { nizacionais que vão levar adiante planos e } \\
\text { parcerias específicas }\end{array}$ \\
\hline $\begin{array}{l}\text { Definir objetivos gerais e desenhar parâmetros } \\
\text { paras as políticas }\end{array}$ & $\begin{array}{l}\text { Operacionalizar grandes objetivos de políticas } \\
\text { públicas em metas específicas e mensuráveis }\end{array}$ \\
\hline $\begin{array}{l}\text { Garantir a autorização formal adequada e os } \\
\text { recursos necessários para conduzir o processo }\end{array}$ & $\begin{array}{l}\text { Garantir a capacidade operacional necessária } \\
\text { tanto de equipamentos e recursos humanos } \\
\text { quanto de incentivos para que a execução seja } \\
\text { bem-sucedida da intenção da política pública }\end{array}$ \\
\hline
\end{tabular}

Fonte: Elaboração própria (2017), a partir de Wu et al. (2014). 
Na implementação das políticas públicas, os agentes implementadores, chamados de servidores públicos, representam a forma em que o Governo encontra para executar suas ações junto aos cidadãos (LEMAN, 2002). Tem-se, nesse momento, um rompimento "para além do Estado", considerando gestores públicos como atuadores nas determinações dos rumos das políticas (FARAH 2011; PARK; RETHEMEYER, 2014). Dessa forma, a atividade de implementar se estende a todos os envolvidos no referido processo, integrando e perpassando do nível político para o organizacional e operativo. Os implementadores precisam compreender a lógica de implementação, transcorrendo além das fontes de financiamentos utilizadas na gestão das políticas públicas. Todavia, necessita-se analisar como outras organizações conduzem programas semelhantes de maneira efetiva no domínio da política (SANDFORT; MOULTON, 2015).

A gestão pública de uma organização pode ser fundamentada em duas vertentes: rotina (quando as melhorias contínuas aprimoram os processos por meio das atividades de gestão de pessoas) e mudança (quando se levantam demandas inadiáveis para o gerenciamento da implementação de políticas públicas). Portanto, o processo de mudança tem como ponto de partida a visão sistêmica, levando em consideração os aspectos como a complexidade e o contexto dinâmico que emergem as estratégias (BERGUE, 2010). O trabalho de implementação é feito pela ação dos gestores públicos, que consiste em iniciativas que visam o enfretamento das mudanças e a resolução dos problemas, tornando uma etapa de complexidade no processo de políticas públicas (WU et al., 2014; SANDFORT; MOULTON, 2015). Para esta pesquisa, adotam-se os gestores públicos como principais atores, já que os mesmos são responsáveis pela administração dos recursos implementados nas organizações.

\section{Metodologia da PESQUiSA}

A metodologia da pesquisa é qualitativa, de natureza descritiva -exploratória (DENZIN; LINCOLN, 2008; FLICK, 2009; GIL, 2010), com o uso da abordagem de estudo de caso (YIN, 2015). Optou-se pelo estudo de casos múltiplos devido a ser analisado sob a ótica várias experiências em diversos contextos organizacionais, permitindo uma maior variabilidade de informações apresentadas sobre 
perspectivas distintas do setor investigado. Dentro dessa tipologia, tem-se o estudo de caso holístico, quando se quer examinar a natureza global de uma organização. Isto é, uma análise mais aprofundada e sistêmica da instituição acessada. Já os casos integrados ocorrem pelos diferentes tipos de condições e por optar em ter subgrupos de casos, proporcionando uma maior variabilidade de informações a fim de dar consistência à investigação (YIN, 2015).

As IFES, que compõem os casos deste estudo, foram selecionadas de maneira não probabilística. Desse modo, a representatividade estatística não é a finalidade para a realização da pesquisa, portanto, tal escolha será guiada pela sensibilidade teórica dos pesquisadores (GASKELL, 2011). Para o mapeamento das IFES, foram acessados os portais de 60 Universidades Federais brasileiras, do período de outubro de 2015 a julho de 2016, a fim de identificar as ações e políticas públicas voltadas para a assistência estudantil. Vale ressaltar que essas informações são públicas, porém não significa que as instituições desempenhem somente as políticas descritas e expostas. Consideraram-se aspectos voltados para estratégias organizacionais que demonstrassem ações diversificadas, inovadoras, complementares e divulgadas nos portais e experiências bem-sucedidas das políticas de assistência estudantil. Os portais dos Institutos Federais, por sua vez, têm uma configuração distinta das Universidades, e de modo geral, as ações não estão facilmente encontradas. Nesse sentido, optou-se pela indicação de gestores da área temática estudada.

Para preservar e garantir a confidencialidade das informações, optou-se por manter o anonimato das organizações pesquisadas, atribuindo assim pseudônimos com as siglas UF à Universidade Federal e IF aos Institutos Federais. Nas premissas que sustentam a abordagem desta pesquisa, classificaram-se como estudo holístico, o IF-Nordeste; e integrados: UF-Norte, UF-Nordeste, US-Sul, UFSudeste e IF-Sudeste. Então, a escolha pelo IF-Nordeste foi feita de caráter intencional por conveniência, além de sua representatividade, motivada ainda pela acessibilidade às informações e aproximação do pesquisador com a instituição.

Na primeira fase da pesquisa (F1), a coleta de dados foi composta por documentos do caso holístico do IF-Nordeste (F1.1) relacionados às políticas de assistência estudantil, por entrevistas semiestruturadas 
(F1.2) e por observação direta (F.1.3). Na segunda fase (F2), a coleta de dados para cada caso integrado consistiu em documentos (F2.1) e entrevistas semiestruturadas com os principais atores sociais do nível organizacional das IFES (F.2.2): UF-Norte, UF-Nordeste, USSul, UF-Sudeste e IF-Sudeste. Buscou-se, a priori, compreender com mais detalhes e aprofundamento o processo de implementação no caso holístico e, posteriormente, verificar como esse entendimento acontecia em outras realidades (casos integrados). As informações da pesquisa trianguladas de múltiplas fontes de dados e informações em documentos, entrevistas e observações, que articuladas e complementares entre si (YIN, 2010), asseguraram a consistência, a viabilidade e a confiabilidade dos resultados deste artigo.

A análise documental, como procedimento metodológico, é adotada na pesquisa, buscando compreender conceitos, grupos sociais, conhecimentos e práticas abordados no contexto político e social nos quais são construídos (CELLARD, 2008). Foi imprescindível o acesso aos documentos das IFES, em ambas as fases, que retratem a realidade do fenômeno investigado, já que os registros descrevem de certo modo as perspectivas da implementação das políticas. Muitos documentos foram do tipo público, sendo apenas dois internos às instituições. Entre os principais temas abordados, estavam os planos de desenvolvimento institucional, sistema de desenvolvimento institucional, procedimento operacional, normativas, guias, regulamentos, planos de ação, resoluções, portarias, relatórios técnicos, de gestão e de reuniões da assistência estudantil. Apreciaram-se os documentos institucionais publicados de 2012 a 2017, identificando, descrevendo e categorizando as principais ações e desafios na implementação das políticas de assistência estudantil, a fim de propor estratégias organizacionais efetivas.

Para garantir os aspectos éticos da pesquisa, todos os entrevistados estavam cientes do objetivo da pesquisa como também dos meios de divulgação dos resultados mediante assinatura do Termo de Consentimento Livre e Esclarecido - TCLE. Foram realizadas sete entrevistas que foram registradas por meio de gravação áudio e transcrição completa mediante agendamento e permissão para a utilização das informações. Os gestores entrevistados têm experiência nas áreas de docência, direção, coordenação e administração, 
entre os quais, ocupam função de reitoria, pró-reitoria, diretoria e coordenadoria nas IFES. A duração média para cada entrevista foi de 40 minutos. Na fase 1, as entrevistas foram feitas individualmente, de maneira presencial, com os gestores da cúpula estratégia da organização. Na fase 2, realizaram-se as entrevistas dos casos integrados de forma individual, pelo software Skype e por telefone. Para cada entrevistado, adotou-se um código "E" seguido de uma numeração para cada gestor (E1, E2, E3, E4, E5, E6 e E7) a fim de garantir o anonimato e sistematizar os conhecimentos gerados.

Na situação empírica deste estudo, a pesquisa de campo utilizou um roteiro de entrevistas semiestruturadas, elaboradas conforme a categorização dos temas abordados no arcabouço teórico e organizado em torno de dois blocos. No primeiro, foram feitas perguntas em torno da análise de integração das políticas, onde se buscou o estabelecimento de opções viáveis, identificação da lógica da mudança e coordenação das atividades de assistência estudantil. O segundo bloco trouxe a análise organizacional da aplicação das políticas, a qual descreveu os fluxos do processo e a avaliação das ações de assistência aos discentes.

Além das entrevistas, foi realizada uma observação direta no campo (FLICK, 2009), haja vista que a participação em reuniões da assistência estudantil gerou ricas oportunidades sobre as deliberações, interações e condições relevantes às questões cruciais do processo de implementação. As informações oriundas da observação foram registradas em caderno de campo e analisadas.

Adotou-se a técnica de análise de conteúdo das informações para a apreciação das discussões, inferências e interpretações. Portanto, as práticas de gestão identificadas tiveram foco interpretativo voltado à geração de um conhecimento aplicado aos atores sociais da pesquisa (COLBARI, 2014). Essa técnica, como abordagem qualitativa, é fundada diante da inferência na presença de um índice (tema, expressão, palavra, frase etc.) e não sobre a frequência da sua aparição em cada texto individual. Desse modo, as unidades de análise do estudo estiveram em consonância com as fases estrututantes (BARDIN, 2011). O material analisado foi primeiramente o conteúdo dos documentos, em seguida, as transcrições das entrevistas e as observações realizadas referentes às políticas de assistência 
estudantil. Assim, foram determinadas as unidades de análise em dimensões e elementos-chave (processos) para categorizar as estratégias propostas.

\section{Estratégias ORganizacionais da IMPlementaÇão de Po- líticas PÚblicas de AssistênCIA Estudantil}

A lógica da efetividade que ampara a implementação de políticas públicas (SANDFORT; MOULTON, 2015), neste artigo, caracteriza-se por duas dimensões: a) análise da integração das políticas e b) análise da aplicação organizacional das políticas de assistência estudantil. A primeira está subdividida em estabelecer opções viáveis, identificar a lógica da mudança e coordenar as atividades; e a segunda, em fluxo do processo e avaliação do programa. Cada uma dessas dimensões possui seus processos de implementação de políticas públicas que, por sua vez, receberam destaques nas discussões, descrições e proposições das estratégias organizacionais da assistência estudantil. Essas estratégias precisam ser implementadas de forma articulada, holística e integrada, e podem se adequar a determinados contextos das IFES. O Quadro 4 resume como as estratégias organizacionais - fruto da análise dos estudos de caso nesta pesquisa - pretendem colaborar no enfrentamento dos possíveis problemas e desafios encontrados na implementação das políticas de assistência estudantil. 
Quadro 4 - Estratégias Organizacionais de Implementação de Políticas Públicas de Assistência Estudantil com base na Perspectiva da Efetividade

\begin{tabular}{|c|c|c|}
\hline Dimensões & Processos & Estratégias propostas \\
\hline \multirow{3}{*}{ Análise da integração } & $\begin{array}{l}\text { Estabelecer op- } \\
\text { ções viáveis }\end{array}$ & $\begin{array}{l}\text { Estabelecer mecanismos administrativos } \\
\text { Estabelecer mecanismos de aprendizagem } \\
\text { Estabelecer mecanismos de comunicação } \\
\text { Estabelecer mecanismos legais }\end{array}$ \\
\hline & $\begin{array}{l}\text { Identificar a ló- } \\
\text { gica da mudança }\end{array}$ & $\begin{array}{l}\text { Identificar metodologias de integração } \\
\text { Identificar metodologias de mapeamento de } \\
\text { demandas } \\
\text { Identificar metodologias para criar redes de } \\
\text { cooperação } \\
\text { Identificar metodologias para a capacitação }\end{array}$ \\
\hline & $\begin{array}{l}\text { Coordenar ativi- } \\
\text { dades }\end{array}$ & $\begin{array}{l}\text { Coordenar atividades de estratégias } \\
\text { Coordenar atividades de cultura organiza- } \\
\text { cional } \\
\text { Coordenar atividades de controle } \\
\text { Coordenar atividades de estrutura organiza- } \\
\text { cional } \\
\text { Coordenar atividades de competências orga- } \\
\text { nizacionais }\end{array}$ \\
\hline \multirow{2}{*}{ Análise da aplicação } & $\begin{array}{l}\text { Fluxo do proces- } \\
\text { so das políticas e } \\
\text { programas }\end{array}$ & $\begin{array}{l}\text { Descrever fluxos de processo de gestão } \\
\text { organizacional } \\
\text { Descrever fluxos de processo de seleção e } \\
\text { monitoramento do público-alvo }\end{array}$ \\
\hline & $\begin{array}{l}\text { Avaliação das } \\
\text { políticas }\end{array}$ & $\begin{array}{l}\text { Avaliar o processo de implementação } \\
\text { Avaliar o nível de integração das políticas e } \\
\text { programas } \\
\text { Avaliar os resultados }\end{array}$ \\
\hline
\end{tabular}

Fonte: Elaboração própria (2017).

Durante o processo de implementação de políticas públicas ocorrem diversos percalços que os gestores precisam enfrentar na execução de suas ações. A complexidade no tratamento dos problemas não é exclusividade do planejamento das políticas. Eles são, categoricamente, mais complexos na implementação, por impossibilitar uma equidade viável para todas as demandas existentes. Dessa forma, a proposição de estratégias torna-se um instrumento profícuo para as políticas públicas diante das dificuldades que podem advir na implementação (CARVALHO; BARBOSA; SOARES, 2010). A diversidade de soluções estratégicas possibilita caminhos nos quais os gestores podem se apropriar, segundo os desafios que lhes concernem. 


\subsection{Análise da Integração das Políticas de Assistência Estu- dantil}

\subsubsection{Estabelecimento de Opções Viáveis}

Durante o processo de estabelecimento de opções viáveis para a implementação efetiva de políticas de assistência estudantil, quatro estratégias são relevantes. A primeira é estabelecer mecanismos administrativos, onde pretende desenvolver ferramentas que proporcionem melhorias contínuas nos processos, bem como, a otimização da gestão dos recursos destinados às políticas de assistência estudantil. Nesse sentido, a implantação e/ou o incremento de um sistema informatizado para a realização dos processos seletivos e o grau de permanência dos discentes que concorrem por bolsas e auxílios dos programas e políticas de assistência estudantil são um ponto estratégico (E6; Relatório para reunião de assistência estudantil do IF-Nordeste). A ação de implantar um sistema informatizado para a realização dos processos de seleção dos estudantes que concorrem aos auxílios é uma alternativa eficaz para agilizar esse trâmite e diminuir a burocracia desnecessária. Além disso, o sistema deve possibilitar a inscrição nos editais, divulgação dos resultados, agendamento de atendimento e outros serviços on-line por meio eletrônico (Observação Direta; Relatório Anual da Pró-Reitoria de Assuntos Estudantis da UF-Sul; Relatório para reunião de assistência estudantil do IF-Nordeste). Então, faz-se importante utilizar um sistema que permita gerenciar os casos nos quais os estudantes que recebem alguma pecúnia das políticas de assistência estudantil permanecem no ensino superior com êxito acadêmico. Nesse processo, a uniformização das políticas de assistência estudantil nos campi das IFES foi sustentada pela maior parte dos entrevistados, por se apresentar como uma característica positiva na implementação das políticas, mesmo considerando as particularidades de cada unidade (E3).

A segunda estratégia consiste em estabelecer mecanismos de aprendizagem que busquem propor a mudança por meio de uma visão sistêmica e integrada entre os níveis de implementação. Esses mecanismos precisam promover a troca de experiências e informações entre os atores sociais, de forma que a implementação das 
políticas seja efetiva. A elaboração e a execução do planejamento sistêmico devem acompanhar as políticas de assistência estudantil nas instituições onde os agentes implementadores da linha de frente e os discentes estejam engajados nessa fase (Plano de Desenvolvimento Institucional do IF Nordeste). No que tange ao processo de aprendizagem, a realização de seminários, fóruns, oficinas e outros meios que exponham as experiências exitosas e os principais gargalos enfrentados, pretende trazer as múltiplas ações ocorridas em contextos diversificados. As especificidades trazidas pela situação vivenciada podem ser difundidas e implementadas pelos demais atores da assistência estudantil (E2; Observação direta).

A terceira estratégia é estabelecer mecanismos de comunicação, a fim de torná-la eficaz, visando integrar a concepção da política e esclarecendo as diretrizes dos programas de assistência estudantil aos atores sociais envolvidos no processo de implementação. Assim, a criação de instrumentos de comunicação organizacional precisa inteirar os usuários das políticas de assistência estudantil sobre as regras e os procedimentos relacionados a esse tema são uma ação que viabiliza essa eficácia. A prática de promover a realização de fóruns, encontros, reuniões ou outros espaços de discussão sobre a assistência estudantil está sendo utilizada por diversas IFES na implementação das políticas (Plano de Desenvolvimento Institucional do IF Nordeste). A criação de manual ilustrativo como forma de comunicação com o público-alvo das políticas de assistência estudantil, informando-o quais são os principais documentos solicitados nos editais, é uma ação estratégica da implementação (Guia de documentos para a solicitação de auxílios da UF-Nordeste). A construção de cartilhas didáticas que tratam da assistência estudantil torna-se uma metodologia utilizada na comunicação, porque visa apresentar os serviços e as respectivas políticas à comunidade acadêmica (Relatório de Gestão da UF-Norte). O incremento das tecnologias da informação e comunicação - TICs - agiliza o processo de implementação das políticas de assistência estudantil, integrando mais as atividades de diversos campi, que podem ser contraditórias e diferentes (E1). Dessa forma, a implementação das políticas de assistência estudantil deve visar à comunicação efetiva com o público-alvo e ao mesmo tempo o processo de concessão de auxílios aos estudantes. 
Dentro do processo de estabelecimento de opções viáveis, a quarta estratégia de estabelecer mecanismos legais é determinante, no sentido de propor a transformação do Decreto 7.234/2010 em lei. Isto quer dizer que a política de assistência estudantil deve se tornar direito garantido aos discentes na permanência universitária. “O governo federal realmente tem que trabalhar essa assistência como uma política, e nós estamos brigando para que ela se transforme em uma política, porque hoje ela é um decreto... e qualquer hora ele pode acabar" (E4). Essa estratégia foi observada em diversas reuniões, haja vista que existe uma expectativa de instabilidade sobre o "futuro" dos recursos do PNAES. As IFES precisam ter um orçamento próprio para que se tenha recursos específicos para a implementação das políticas de assistência estudantil. Com o processo de redemocratização do ensino superior, por meio da reestruturação e expansão das Universidades Federais - REUNI (BRASIL, 2007), os estudantes tiveram cada vez mais acesso às IFES. No entanto, a dificuldade de permanecer e/ou de concluir o curso de graduação com qualidade preconiza a necessidade de propor a transformação das políticas de assistência estudantil na elaboração de uma lei. Esse fator como uma estratégia seria um avanço para dar garantias institucionais ao PNAES.

\subsubsection{Identificação da Lógica de Mudança Organizacional}

No processo de identificação da lógica de mudança organizacional, foram descritas e analisadas quatro estratégias. A proposição de integração entre os atores sociais ligados à organização é uma tática crucial para a primeira estratégia de identificar metodologias de integração. A metodologia de criação de fóruns, seminários, encontros, reuniões ou outros espaços de discussão sobre a assistência estudantil de assistência estudantil, no âmbito institucional, é utilizada estrategicamente (Plano de Desenvolvimento Institucional do IF Nordeste). Outro fator é relacionar o trabalho da assistência estudantil com recursos humanos disponíveis, buscando a interdisciplinaridade dos profissionais em diversas áreas do conhecimento, agregando a implementação de políticas (Políticas de Assistência Estudantil consoantes na Resolução do IF Sudeste). A interligação com outras áreas da organização tornou-se uma realidade nas IFES, 
já que a assistência estudantil também se relaciona com outras finalidades institucionais: ensino, pesquisa e extensão universitária (E1; E6; Relatório de Gestão da UF-Norte). O setor responsável pela assistência estudantil alcança áreas que são voltadas para acompanhar o estudante na permanência durante a graduação, procurando executar um trabalho integrado na implementação das políticas. Então, as políticas de assistência estudantil são estratégias porque englobam desde a concessão pecuniária das bolsas e auxílios até o acompanhamento do rendimento acadêmico dos alunos (E4; Observação Direta).

Outra estratégia é a de identificar metodologias de mapeamento de demandas, visando à criação de dispositivos efetivos, principalmente para os estudantes em vulnerabilidade socioeconômica que acessam aos programas e políticas de permanência (Plano de Desenvolvimento Institucional do IF Nordeste). Além disso, deve haver o estabelecimento de uma agenda específica de atendimentos e demandas emergenciais a partir da identificação e registros dos atores envolvidos nas políticas de assistência estudantil (Relatório Anual da Pró-Reitoria de Assuntos Estudantis da UF-Sul). Instituir canais como help desk, redes sociais, e-mails e outros, que estabeleçam de maneira mais direta a identificação dessas necessidades dos estudantes, onde a gestão das políticas de assistência ao discente tenha conhecimento das questões mais emergenciais (E1). A formação de comissões específicas para diagnosticar problemas voltados para a assistência estudantil, como trancamento de matrícula e evasão escolar, foi uma solução efetiva explicitada (Observação Direta). O trabalho integrado das comissões com os atores sociais envolvidos busca desenvolver ações que produzam resultados almejados pela gestão das IFES.

Ainda no processo de lógica de mudança, o estímulo à concepção de redes, apontando a aprendizagem intra e interorganizacional, proporciona a estratégia de identificar metodologias para criar redes de cooperação em relação à temática de assistência estudantil. A conexão dessa área temática com outros campos finalísticos das IFES, como, extensão, cultura, artes, esporte, pesquisa e ensino, pode ser um elemento estratégico na implementação das políticas. Desse modo, as normativas da assistência estudantil podem citar áreas para além 
das que estão explicitadas no PNAES. Tem-se a interdisciplinaridade das ações de assistência estudantil perante o pluralismo de ideias advindas das redes de cooperação entre os atores sociais (Plano de Desenvolvimento Institucional do IF Nordeste; Observação Direta). Assim, pode-se mencionar o estímulo às interações e reuniões para discutir os procedimentos administrativos, os resultados esperados e alcançados, o tempo e o prazo de execução das tarefas, os responsáveis e a integração entre os setores (Relatório de Gestão da UF-Norte). Incluir o público-alvo, que são os discentes, nas redes de cooperação interna à organização, foi uma das propostas dos entrevistados. Na medida em que esse público pode opinar e colaborar sobre as ações das políticas de assistência estudantis, as consequências são eficazes. Isso é possível, por exemplo, quando o grêmio estudantil se envolve na divulgação e nas discussões da assistência ao aluno, almejando melhorias na implementação. Outra menção foi feita em relação a firmar parcerias com empresas privadas, uma vez que essas podem ofertar estágios remunerados, desconto em cursos e materiais aos estudantes em situação de vulnerabilidade e garantir a permanência dos mesmos nas instituições. $\mathrm{O}$ desenvolvimento de redes com órgãos públicos municipais e estaduais para estabelecer vínculos e prestar atendimentos que possam auxiliar nas ações da assistência estudantil nas IFES é uma forma de garantir a permanência do discente na graduação. "É como se fosse uma creche, que a prefeitura oferece o prédio da universidade e os servidores são da prefeitura, para auxiliar filhos de alunos, filhos de servidores e comunidade carente lá do campus" (E6). A importância dessas redes de cooperação foi abordada, haja vista que as interações internas e externas são estratégicas na permanência dos estudantes. As ações em redes, nesse sentido, devem garantir atendimentos que as IFES não conseguem executar diante de suas limitações de pessoal e de estrutura, como atendimentos psicossociais, atenção e proteção à saúde da mulher (E7).

A quarta estratégia almeja identificar metodologias para a capacitação no atendimento das necessidades de capacitação dos implementadores de políticas de assistência estudantil como uma ferramenta necessária na gestão pública. Então, os planos de capacitação para servidores vinculados à assistência estudantil devem descrever o 
caminho no qual as organizações pretendem alcançar resultados efetivos (Relatório para reunião de assistência estudantil do IF Nordeste). O fortalecimento dos departamentos e coordenações de apoio é imprescindível para instituições que busquem valorizar os serviços prestados à população-alvo (Observação Direta; Plano de Desenvolvimento Institucional do IF Nordeste). As capacitações, diretamente ligadas ao desenvolvimento de pessoas, devem buscar formações que sejam relacionadas à assistência estudantil. Destarte, participações em eventos voltados à temática da assistência estudantil e encontros entre os próprios colaboradores funcionam como treinamento para os agentes implementadores dessa política. A solução proposta frente à necessidade de capacitação dos executores da linha de frente das políticas de assistência estudantil é trazer cursos específicos da área para a própria IFES, sem que os agentes precisem deslocar-se de suas unidades. Inclusive foi ressaltado que os órgãos de controle sugerem que as capacitações sejam realizadas também na sede da instituição, uma vez que um número maior de colaboradores pode participar dispensando custos de locomoção (E1). Tanto nos portais das IFES quanto nas entrevistas, verificou-se que há uma consonância em relação aos profissionais que trabalham com a assistência estudantil estarem ligados às áreas de psicologia, enfermagem, assistência social, pedagogia e nutrição (E1; E2; E3; Observação Direta). Esses funcionários acabam desempenhando atividades operacionais além de suas funções nas quais foram designados. No entanto, é estratégica a imersão de pessoas com formação diferente das que convencionalmente se encontram (enfermeiros, psicólogos, assistentes sociais, nutricionistas e pedagogos) na assistência estudantil, com natureza técnica e habilidades pautadas na gestão das políticas no intuito de desempenhar as tarefas gerenciais, como: recursos humanos, comunicação social, administração, gestão pública e outros.

\subsubsection{Coordenação das Atividades}

Ao longo do processo de coordenação das atividades da assistência estudantil, propomos cinco estratégias de implementação efetiva das políticas. A primeira delas é coordenar as atividades estratégicas que buscam a proposição de objetivos e metas alcançáveis e compreensíveis perpassando ao que está descrito em normativas e 
resoluções relacionadas à finalidade organizacional. O estabelecimento de um plano de gestão para guiar as estratégias das políticas de assistência estudantil auxilia na coordenação das atividades técnicas dos implementadores. A criação de manual ilustrativo, a fim de demonstrar ao público-alvo das políticas de assistência estudantil, sobre quais os principais documentos, normas e regras contidas nos editais para sanar as dúvidas que apresentam maiores dificuldades e/ou erros na entrega da documentação solicitada. Contendo, assim, o detalhamento e o fluxo das etapas com a finalidade de facilitar a efetividade do processo e evitar retrabalho dos implementadores (E7; Observação direta; Guia de documentos para solicitação de auxílios da UF-Nordeste). A criação de planos de ação também é um mecanismo de coordenação, que identifica o responsável, o período de execução, os objetivos, as estratégias e os indicadores a fim de melhorar o processo de implementação das políticas de assistência estudantil (Plano de ação da UF-Centro-Oeste).

A segunda estratégia, denominada de coordenar atividades de cultura organizacional, considera os fatores relacionados à cultura interna no desempenho e na execução das atividades desenvolvidas pela assistência estudantil. Dessa forma, promover e incentivar a mudança cultural e atividades desenvolvidas pelos servidores para a gestão por resultados (Relatório de Gestão UF-Norte). Então, os gestores organizacionais devem preconizar a cultura de implementação de políticas públicas de assistência estudantil voltada para gerir os resultados e impactos das ações. A motivação, o senso de pertencimento e a responsabilidade dos implementadores das políticas de assistência estudantil foram temáticas presentes nas entrevistas com os gestores. As políticas que almejam a permanência dos discentes no ensino superior, muitas vezes, são encaradas tanto pelos funcionários quanto pelos estudantes, como sendo exclusivamente pautadas pelo fornecimento dos recursos financeiros e orçamentários do governo. Entretanto, a sensibilização do servidor público na prestação dos serviços relacionados à assistência estudantil é uma ação que pode gerar benefícios para a organização (E1; E2; Observação Direta). Esse é um fator cultural que precisa ser introduzido no cenário da assistência estudantil das IFES, inclusive como uma forma de enxergar além dos recursos governamentais. 
A terceira estratégia efetiva é coordenar atividades para estabelecer o controle da gestão por meio da criação de mecanismos de supervisão de atividades relacionadas à implementação de políticas públicas de assistência estudantil. As IFES precisam investir continuamente em sistema informatizado e fluxos de controle, de acordo com normas e critérios estabelecidos com todas as especificações e pré-requisitos ao público-alvo para participação nos programas de assistência estudantil. Além disso, a elaboração de relatórios que acompanhem sistematicamente os impactos das políticas e a permanência dos estudantes nas IFES precisa funcionar como uma rotina gerencial dos gestores públicos (Relatório Anual da Pró-Reitoria de Assuntos Estudantis da UF-Sul; Resolução nº. 083/2016, que regulamenta o processo de avaliação socioeconômica da UFCentro-Oeste). É estratégico o controle na seleção dos discentes diretamente impactados pelas políticas de assistência estudantil, sobretudo de que maneira as IFES podem adotar dispositivos de segurança para tornar o processo efetivo. "Os impactos das políticas são muito positivos, ainda mais quando você verifica que existe um acompanhamento da CGU, de auditorias internas. A gente já viu na mídia várias universidades que estão sendo investigadas, por uso inadequado dos recursos do PNAES" (E6). O controle serve ainda como estratégia de prevenção de possíveis fraudes, por intermédio de acesso a bancos oficiais, como o da receita federal. Isso permitiria uma avaliação mais consistente, por parte dos profissionais da assistência estudantil, do perfil de vulnerabilidade: "tem muita situação que nós percebemos aqui, de alunos que tentam fraudar as avaliações. Eles apresentam documento falso ou omitem informações que não tem como elas descobrirem isso apenas analisando a documentação" (E6). Um fator relevante é o controle social que pode ser exercido pelos atores (gestores, discentes, comunidade e sociedade civil como um todo) relacionados à assistência estudantil, por meio do aumento da promoção da transparência pública acerca da disposição das informações sobre os desdobramentos do PNAES tanto nacionalmente (governo federal) quanto localmente (IFES). Tem-se a questão da publicização não só dos recursos orçamentários e financeiros, mas também das ações das políticas de assistência estudantil, de modo que a sociedade as legitime. A sociedade sente 
os impactos dessa democratização do acesso e da permanência dos estudantes em vulnerabilidade socioeconômica na universidade, por essa razão, deve haver uma ampla divulgação e esclarecimentos sobre "o quê" e "como" o recurso pode oferecer e o seu resultado (E6; Observação Direta).

Nesse processo, torna-se estratégico na implementação das políticas, a forma de coordenar atividades de estrutura organizacional por meio da elaboração das atribuições das áreas relacionadas à assistência estudantil (quarta estratégia). Desse modo, a estruturação do setor de assistência estudantil nas IFES necessita determinar a divisão dos papéis e atividades conforme organograma organizacional de modo que as finalidades fiquem "claras" para os gestores e os implementadores das políticas (Observação Direta; Relatório para reunião de assistência estudantil-IF Nordeste). A distinção entre as competências e os papéis dos atores sociais ligados à assistência ao discente facilita, inclusive, a definição de estratégias mais assertivas para cada grupo à medida que considera as singularidades e os desafios pormenores confrontados por eles.

A quinta estratégia é coordenar atividades de competências organizacionais que têm como técnica selecionar e desenvolver pessoas de habilidades, competências e cargos específicos ao processo de implementação das políticas de assistência estudantil. Nota-se, de modo geral, que há explicitamente uma necessidade de reestruturação e adequação do quadro de pessoal (Relatório para reunião de assistência estudantil - IF Nordeste). No desempenho das atividades, os implementadores das políticas de assistência estudantil acabam sendo designados para tarefas operacionais, neste caso as suas competências específicas ficam comprometidas (Observação Direta). Todos os gestores (E1, E2, E3, E4, E5, E6 E E7) mencionaram e enfatizaram a insuficiência do quadro de pessoal no setor de assistência estudantil, sobretudo os que desempenham atividades específicas aos discentes. Como se trata de instituições públicas federais, os servidores são selecionados por concurso público. O departamento de assistência estudantil demanda da gestão de pessoas, geralmente, profissionais das áreas de psicologia, assistência social, nutrição, enfermagem e pedagogia. A formação da equipe multiprofissional é importante para garantir qualidade no atendimento ao discente 
de modo que acompanhe a sua permanência durante a graduação.

\subsection{Análise Organizacional da Aplicação das Políticas de Assistência Estudantil}

\subsubsection{Fluxo do Processo das Políticas e Programas}

A estratégia de descrever fluxos de processo de gestão organizacional é efetiva quando ocorrem a identificação e a descrição dos instrumentos com a finalidade de padronizar o gerenciamento do(s) projeto(s) da assistência estudantil. Isso é possível com a criação de um fluxo operacional que objetive o delineamento das etapas. Adotar procedimentos que padronizem as operações descrevendo o início e o fim do processo visa uma gestão efetiva da política de assistência estudantil uma vez que sistematiza e acompanha todas as atividades ligadas a essa área (Procedimento Operacional Padrão - POP da UF Norte). Além de decreto, leis, normas e regras acerca das políticas de assistência estudantil, algumas IFES desenvolvem ferramentas específicas para o planejamento das atividades. Por exemplo, a ferramenta do POP: "lá estão descritas todas as etapas que nós desenvolvemos no nosso trabalho. Informa sobre a base legal, quais são as diretrizes, quais são os objetivos que devemos atingir, quais são os critérios que os alunos devem atender para participar dos programas" (E4). Esse tipo de dispositivo colabora para a gestão das políticas de assistência estudantil, permitindo que qualquer servidor instruído consiga visualizar os processos com as atividades e sequências descritas para a implementação.

A estratégia de descrever fluxos de processo de seleção e monitoramento do público-alvo convém para a identificação e a descrição de sistemas de informação que proporcionem agilidade nos trâmites de seleção e monitoramentos dos discentes ligados à assistência estudantil. Geralmente, a seleção dos alunos é feita por meio de edital onde constam as regras e todo procedimento para concorrer aos auxílios oferecidos pelos programas de assistência estudantil. Do mesmo modo, o desenvolvimento de um fluxo operacional com o objetivo de selecionar o público-alvo das políticas de assistência estudantil é um resultado prático da implementação efetiva (Sistema de Desenvolvimento Institucional - Procedimento Operacional da 
UF Nordeste; Procedimento Operacional Padrão - UF Norte). Tem-se a exemplificação dessa estratégia de seleção e monitoramento dos discentes na fala de um entrevistado: "Temos um processo de renovação (online) onde todos os discentes beneficiários da assistência estudantil que, além de informarem como foi o semestre (atividades acadêmicas e pedagógicas), podem informar impactos nos aspectos sociais, familiares e de saúde que influenciaram a sua trajetória" (E5). Esses estudantes com problemas particulares devem ser encaminhados e acompanhados pela equipe de profissionais específicos já que esses fatores podem ser determinantes na sua permanência enquanto universitários(as). Os instrumentos supracitados são formas de padronizar os processos de implementação das políticas de assistência estudantil, principalmente as atividades que demandam maiores esforços para a execução. Desse modo, as políticas podem ter continuidade mesmo quando demais funcionários possam vir integrar a equipe.

\subsubsection{Avaliação das Políticas}

Foram delineadas três estratégias de avalição das políticas de assistência estudantil que devem ser implementadas efetivamente no contexto das IFES. A primeira estratégia é avaliar o processo de implementação que propõe melhorias na concepção dos programas implementados pela assistência estudantil. A dinâmica de implantar uma comissão permanente de avaliação da assistência estudantil com projeto de atuação nos Campi das IFES é uma conduta eficaz (Plano de Desenvolvimento Institucional do IF Nordeste, p. 32). Para suprir a necessidade de monitoramento da implementação das políticas, podese conceber a avaliação como processo contínuo a fim de verificar a conformidade dessas políticas com o PNAES, inclusive com revisões periódicas frente aos resultados indesejados (Resolução 101/2013 do IF-Sudeste). Há uma consonância dos entrevistados em afirmar que, devido à expansão do ensino superior nas instituições federais, a demanda dos estudantes ligados à assistência estudantil aumentou e o número de servidores é insuficiente para atender. Essa carência de recursos humanos na implementação das políticas estudantis é um dos maiores gargalos para os gestores públicos. Por isso, a adequação do quadro de pessoal da área de assistência ao discente é considera- 
da estratégica visto que se faz imprescindível diante do aumento da oferta de vagas nas IFES (Observação direta; E1; E2; E3; E4; E5; E6; E7). Então, o público-alvo da política não tem um atendimento pleno devido a essas limitações de pessoal o que gera uma falta de acompanhamento, como explica um entrevistado: "a questão de pessoal é insuficiente. Não há uma sistemática para acompanhar. Deveria ter uma forma de ouvir aluno a aluno. A demanda é muito alta. Seria uma oportunidade [...] teríamos um norte melhor" (E1). Tem-se ainda a necessidade de avaliar o processo de implementação de maneira holística e uniforme, embora exista o Decreto 7.2344/2010 que estabelece o PNAES, cada IFES tem a discricionariedade sobre a metodologia de avaliar e selecionar o público-alvo. Existem particularidades em cada instituição, no entanto, isso não inviabilizaria um padrão geral na avaliação das políticas de assistência estudantil já que estamos diante de um programa nacional. “O próprio FONAPRACE deveria estabelecer uma política mínima. Toda instituição tem que fazer no mínimo isso! Você pode, dependendo da demanda individual ou da demanda local, fazer alguma alteração" (E6).

A segunda estratégia consiste em avaliar o nível de integração do programa, onde os gestores do nível organizacional mapeiam as principais dificuldades do setor da assistência estudantil para buscar soluções de melhoria. Essa visão deve ser transversal, de modo que os problemas enfrentados pelos funcionários da linha de frente sejam diagnosticados e considerados na tomada de decisão dos rumos das políticas de assistência estudantil. Geralmente, os relatórios e as necessidades são explicitados quando solicitados e/ou em reuniões periódicas. Desse modo, a criação de mecanismos que acompanhem e avaliem o trabalho dos implementadores e sua integração com a gestão de políticas públicas de assistência estudantil para que se obtenham integração e efetividade nas ações (Observação direta; E1; E2; E3; E4; E5; E6; E7). As avaliações sobre as condições dos atores que implementam as políticas de assistência devem ser analisadas de maneira integrada e sistêmica, de modo que os relatórios sejam elaborados tanto sob a ótica quantitativa quanto qualitativa, objetivando gerar métodos avaliativos diversificados.

A terceira estratégia é avaliar os resultados das políticas implementadas pela assistência estudantil com o propósito de identificar os 
principais impactos que elas ocasionam na geração de valor público. Logo, criar indicadores de avaliação e de referência para a matriz orçamentária (Plano de Desenvolvimento Institucional do IF Nordeste) bem como monitorar os impactos do público-alvo por meio de um instrumento de sistema operacional têm sido ações profícuas na implementação das políticas (Sistema de Desenvolvimento Institucional - Procedimento Operacional da UF Nordeste). A proposta de incluir cláusulas nos editais de empresas prestadoras de serviços, que visem a avaliação dos serviços contratados, como por exemplo, fornecedores de alimentos para o Restaurante Universitário, é uma alternativa de gestão da assistência estudantil (Relatório Técnico do Teste de aceitabilidade da UF Norte). Um entrevistado explica: “colocamos de três a quatro perguntas para que o nosso aluno pudesse avaliar o nosso trabalho. Isso é interessante para prestar contas para os atores envolvidos e para os órgãos de controle (CGU, TCU)" (E4). Os impactos das políticas de assistência estudantil determinam um parâmetro, tanto para quem implementa as ações quanto para o público-alvo, sendo estratégico na medida em que é verificado por intermédio das avaliações dos resultados.

\section{DisCUSSÃo E IMPACTOS}

A repercussão das estratégias pode ser divergente, haja vista os múltiplos interesses dos atores sociais envolvidos no processo de implementação. Na tentativa de mitigar possíveis impasses, faz-se necessário identificar estratégias admissíveis, interesses e recursos que os atores são capazes de mobilizar a partir da sua "posição institucional" (SUBIRATS et al., 2012). Dessa forma, mapear as estratégias torna-se um caminho possível para contrapor os desafios que impedem uma implementação efetiva já que inexiste uma maneira "perfeita" de implementar políticas públicas.

Os impactos desta pesquisa se dão por meio da implementação efetiva das estratégias de assistência estudantil contidas nas dimensões de análise organizacional da integração e de aplicação das políticas. Essas dimensões trouxeram dois processos nos quais as estratégias organizacionais foram detalhadas.

Primeiramente, os processos que estabeleceram opções viáveis, identificaram a lógica da mudança e propuseram coordenar as ativida- 
des, procuram resolver os principais desafios dos gestores, a saber: falha no gerenciamento de demandas inadiáveis dos estudantes, insuficiência e/ou limitação de recursos financeiros e humanos, ineficácia dos mecanismos de comunicação dos objetivos, disfunção da burocracia, carência de sistemas informatizados, ausência de coordenação de rede, falta de maior transparência, insuficiência na formação dos implementadores e outros. Assim, as estratégias de implementação propuseram os dispositivos de administração, aprendizagem, comunicação, metodologias de integração, mapeamento de demandas, criação de redes, capacitação, cultura organizacional, controle, estrutura e competências organizacionais das políticas de assistência estudantil no nível organizacional.

Posteriormente, os processos que analisaram a aplicação dos fluxos e da avaliação das políticas diante dos desafios relacionados à falta de uniformidade das atividades organizacionais e das políticas, à ausência de avaliações e outros mecanismos formais de monitoramento e controle dos resultados da implementação das políticas de assistência estudantil. Dessa forma, foram propostas estratégias organizacionais que contemplassem os mecanismos de gestão, seleção e monitoramento do público-alvo, nível de integração, resultados e avaliação do processo de implementação.

Esses desafios podem acontecer de maneira isolada ou não, no entanto, observou-se uma forte correlação no nível organizacional ancorada no contexto das políticas de assistência estudantil nas IFES. Por essa razão, buscamos identificar estratégias efetivas nas quais a gestão das políticas de assistência estudantil possa subsidiar as decisões na implementação.

Esta pesquisa visa atender às demandas da gestão pública sobre as práticas de implementar com efetividade as estratégias bem como, melhorar a execução no campo das políticas de assistência estudantil. Para os formuladores de políticas de assistência estudantil, as estratégias indicadas impactam na elaboração de ações a serem indicadas aos executores das mesmas. A formação e o desenvolvimento das políticas, dos instrumentos e dos recursos disponibilizados necessitam ser aprimorados com os conhecimentos aplicados apresentados neste estudo. Por conseguinte, a tomada de 
decisão pode garantir melhor performance das políticas públicas de assistência estudantil desses formuladores.

Os impactos das estratégias organizacionais podem ocasionar melhorias para os seus implementadores: gestores, funcionários da linha de frente, público-alvo (discentes) e demais atores sociais (docentes, servidores públicos, terceirizados, comunidade) relacionados com a assistência estudantil. Como o foco deste artigo está no nível organizacional, a gestão das IFES pode apropriar-se das estratégias propostas nos resultados para superar seus desafios e alcançar a mudança almejada, otimizar os recursos do PNAES e integrar os atores envolvidos, considerando o conjunto no qual se inserem. Além dos impactos de gestão organizacional, com a implementação efetiva das políticas de assistência estudantil, as IFES podem melhorar e reduzir a evasão dos estudantes, auxiliando-os na permanência durante a graduação.

As estratégias deste artigo foram levantadas sistematicamente diante dos desafios encontrados nos diversos contextos das IFES de todas as regiões do Brasil, o que garante a consistência e a inovação desses resultados. Isso confirma a busca pelas práticas de implementação efetiva e a integração das informações relacionadas às políticas de assistência estudantil. Os desafios enfrentados na implementação das políticas, que foram identificados nos documentos, nas entrevistas e nas observações, geram impactos diretos para as IFES. Todavia, sistematizá-los no processo de implementação das políticas de assistência estudantil, de modo geral, a partir das estratégias organizacionais, ajuda a superá-los.

Dessa maneira, o governo e as IFES podem agregar valor para os atores sociais envolvidos no processo de implementação a partir da replicação dos resultados do artigo. Nessa concepção, fez-se imprescindível observar que uma ou mais estratégias podem ser pertinentes a múltiplos desafios distintos, sem que haja necessariamente uma relação mutuamente excludente entre os elos. Para cada estratégia destacada, tem-se diversas ações que a sustentam e detalham as formas de alcançá-la tanto na análise quanto na aplicação das políticas no nível organizacional. 


\section{ConClusão}

A contribuição deste artigo foi construir um referencial de implementação de política pública com foco na perspectiva da efetividade e adaptar ao contexto das políticas de assistência estudantil. Além disso, buscamos contribuições práticas por intermédio das estratégias organizacionais que ajudam os gestores públicos a melhorarem a implementação das políticas. As estratégias organizacionais discutidas, descritas e propostas tiveram o intuito de demonstrar os dispositivos encontrados nas práticas dos gestores das IFES no contexto das políticas de assistência estudantil. Diante dos investimentos governamentais voltados para a permanência dos estudantes no ensino superior, essas estratégias podem otimizar a implementação dos recursos, enfrentar, mitigar e/ou resolver os desafios encontrados pelos gestores de nível organizacional de maneira integrada.

O papel das organizações no processo de implementação na autorização e prestação de serviços é relevante para a integração com as políticas e programas. A sistemática dessas estratégias foi firmada a partir da proposição de fatores que almejem a mudança e os resultados para a efetividade das políticas de assistência estudantil. Assim, descrevemos as estratégias de nível organizacional como dispositivos para compreender as condições desejadas pelas IFES, em duas vertentes: (a) análise da integração das políticas; e (b) análise organizacional da aplicação das políticas.

A finalidade do nosso artigo foidiscutir, descrever e propor estratégias organizacionais para auxiliar os gestores na implementação das políticas de assistência estudantil com o enfoque da perspectiva da efetividade. No primeiro bloco, demonstramos as estratégias de estabelecimento de opções viáveis que trouxeram os mecanismos administrativos, de aprendizagem e de comunicação; de identificação da lógica da mudança que identificaram metodologias de integração, mapeamento de demandas, criação de redes e capacitação; e de coordenação das atividades que discutiram estratégias, cultura organizacional, estabelecer o controle, estrutura e competências organizacionais. O segundo bloco foi composto pelos fluxos do processo das políticas que descreveram procedimentos de gestão organizacional, seleção e monitoramento do público-alvo; e a avaliação das políticas sobre o 
processo de implementação, nível de integração e resultados (grifos do autor). Tanto o governo quanto as IFES devem adotar alternativas efetivas para otimizar os recursos da assistência estudantil, como demonstrado nas estratégias deste estudo, desmistificando a ideia de que as políticas são meramente "assistencialistas" e podem gerar valor público na permanência dos discentes no ensino superior.

As IFES possuem regras e normas próprias de implementar, por meio da disposição das políticas de assistência estudantil, diante da realidade orçamentária e estrutural de cada uma. As estratégias organizacionais construídas, neste campo de estudo, podem se adequar às circunstâncias variadas conforme a necessidade da gestão que as implementem. Neste artigo, embora tenha a intenção de impactar efetivamente o modo de implementar as políticas de assistência estudantil, não esgotamos todas as possibilidades de imersão no campo empírico de investigação sobre esse tema.

\section{REFERÊNCIAS}

BARBOSA VICENTE, V. M. A análise de políticas públicas na perspectiva do modelo de coalizões de defesas. Revista de Políticas Públicas. São Luís, v. 19, n. 1, p. 77-90, jan./jun. 2015.

BARDIN, L. Análise de conteúdo, 2. reimp., 1. ed. São Paulo: Edições 70, 2011.

BATEMAN, T. S.; SNELL, S. A. Administração: novo cenário competitivo, 2. ed. São Paulo: Atlas, 2006

BERGUE, S.T. Cultura e mudança organizacional. Florianópolis: Departamento de Ciências da Administração / UFSC; [Brasília]: CAPES: UAB, 2010.

BERGUE, S. T. Gestão estratégica e políticas públicas: aproximações conceituais possíveis e distanciamentos necessários. Contabilidade, Gestão e Governança. Brasília, v. 16, n. 2, p. 77-93, mai./ago., 2013.

BRASIL. Decreto no. 7.234, de 19 de julho de 2010, que institui o Programa Nacional de Assistência Estudantil - PNAES. Diário Oficial [da] República Federativa do Brasil. Brasília, DF, 19 jul. 2010. Disponível em: <www.planalto.gov.br/ccivil_03/_Ato2007-10/2010/Decreto/ D7234.htm>. Acesso em: 5 abr. 2016.

CARVALHO, M. L.; BARBOSA, T. G. C. G.; SOARES, J. B. Implementação de política pública: uma abordagem teórica e crítica. In: X Coloquio Internacional sobre Gestión Universitaria en América del Sur. 2010, Mar del Plata, Argentina. Anais... Mar del Plata: Universidad Nacional de Mar del Plata, dez. 2010.

CELLARD, A. A análise documental. In: POUPART, Jean. A Pesquisa Qualitativa: enfoques epistemológicos e metodológicos. Petrópolis: Vozes, 2008, p. 295-316. 
COLBARI, A. A análise de conteúdo e a pesquisa empírica qualitativa. In: SOUZA, E. M. (Org.). Metodologias e analíticas qualitativas em pesquisa organizacional: uma abordagem teórico conceitual. Vitória: EDUFES, 2014.

DENZIN, N. K.; LINCOLN, Y. S. O Planejamento da pesquisa qualitativa teorias e abordagens, 2. ed. Porto Alegre: Artmed, 2008.

DIAS, A. A. Da educação aos direitos humanos como princípio educativo. In: SILVEIRA et al. (Orgs.). Educação em Direitos Humanos: fundamentos teóricos-metodológicos. João Pessoa: Universitária, 2007, p. 441-456.

ETZIONI, A. Reexame da estratégia mista de decisão. In: HEIDEMANN, Francisco G.; SALM, José Francisco (Orgs.). Políticas públicas e desenvolvimento: bases epistemológicas e modelos de análise. 3.ed. Brasília: Editora Universidade de Brasília, 2014, pp. 243-259.FARIA, C. A. P. (Org.). Implementação de políticas públicas: teoria e prática, 1. ed. Belo Horizonte: Editora PUC MINAS, 2012.

FARAH, M. F. S. Administração pública e política pública. Revista de Administração Pública, v. 45, n. 3, p. 813-836, 2011.

FLICK, U. Introdução à pesquisa qualitativa. Tradução Joice Elias Costa, 3. ed. Porto Alegre: Artmed, 2009.

FLIGSTEIN, N.; McADAM, D. Toward a General Theory of Strategic Action Fields. Sociological Theory, v. 26, n. 1, p. 1-26, 2011.

FLIGSTEIN, N.; McADAM, D. A theory of fields. Oxford: Oxford University Press, 2012.

FREY, K. Políticas públicas: um debate conceitual e reflexões referentes à prática da análise de políticas públicas no Brasil. Planejamento e Políticas Públicas. Brasília, n. 21, p. 211-259, jun., 2000.

GASKELL, G. Entrevistas Individuais e Grupais. In: BAUER, M. W.; GASKELL, G. (Orgs.). Pesquisa Qualitativa com Texto, Imagem e Som: Um manual Prático, 9. ed. Petrópolis: Vozes, 2011.

GIL, A. C. Como elaborar projetos de pesquisa, 5. ed. São Paulo: Atlas, 2010.

HILL, M. The policy process: a reader. Hertforsdhire: Harvester Wheatsheaf, 1993.

HILL, M.; HUPE, P. Implementation Public Policy: an introduction to the study operational governance, 3. ed. London: Sage Publications, 2014.

LEMAN, C. K. Direct government. In: SALAMON, L. The tools of government: a guide to the new governance. Oxford: Oxford University Press, 2002, p. 48-79.

LIMA, L. L.; D'ASCENZI, L. Implementação de Políticas Públicas: perspectivas analíticas. Revista de Sociologia e Política. Curitiba, v. 21, n. 48, p. 101-110, dez. 2013.

LIMA, W. A. S.; DAVEL, E. Implementação de Política Pública de Assistência Estudantil nas IFES: a perspectiva da efetividade e suas virtudes. In: XVI Colóquio Internacional de Géstion Universitaria - CIGU, 2016. Arequipa, Peru. Anais... Arequipa: UFSC, 2016. Disponível em: <https://repositorio.ufsc.br/xmlui/handle/123456789/171277>. Acesso em: 20 jan. 2017. 
OLLAIK, L. G.; MEDEIROS, J. J. Instrumentos governamentais: reflexões para uma agenda de pesquisas sobre implementação de políticas públicas no Brasil. Revista de Administração Pública. Rio de Janeiro, v. 45, n. 6, p. 1943-1967, 2011.

PEREZ, J. R. R. Por que pesquisar implementação de políticas educacionais atualmente? Educação \& Sociedade. Campinas, v. 31, n. 113, p. 1.179-1.193, 2010.

PRESSMAN, J. L.; WILDAVSKY, A. Implementation: how great expectations in Washington are dashed in Oakland, 3. ed. Berkeley: University of California, 1984.

SAMPARI, R. H.; COLLADO, C. F.; LUCIO, P. B. Metodologia de Pesquisa, 3. ed. São Paulo: McGraw-Hill, 2006.

SANDFORT, J. R.; MOULTON, S. Effective Implementation in Practice: Integrating Public Policy \& Management. San Francisco, CA.: Jossey-Bass, 2015.

SARAIVA, E.; FERRAREZI, E. (Orgs.). Políticas Públicas. Brasília: ENAP, 2006.

SAUNDERS, R. P. Implementation monitoring and process evaluation. Los Angeles: University of South Carolina Press, 2016.

SECCHI, L. Políticas públicas: conceitos, esquemas de análise, casos práticos, 2. ed. São Paulo: Cengage Learning, 2014.

SUBIRATS, J.; KNOWEPFEL, P.; LARRUE, C.; VARONE, F. Análisis y gestión de políticas públicas, 2. ed. Barcelona: Editorial Planeta, 2012.

WU, X.; RAMESSH, M.; HOWLETT, M. FRITZEN, S. Guia de políticas públicas: gerenciando processos. Brasília: Enap, 2014.

YIN, R. K. Estudo de caso: planejamento e métodos, 5. ed. Porto Alegre: Bookman, 2015.

Recebido em: 5-4-2017

Aprovado em: 28-08-2017

Avaliado pelo sistema double blind review.

Editor: Elmo Tambosi Filho

Disponível em http://mjs.metodista.br/index.php/roc 